\title{
Hemolytic toxicity and nutritional status of Prymnesium parvum during population growth
}

\author{
Theodore R. Skingel ${ }^{1,2}$, Sandra E. Spencer ${ }^{1}$, Cuong Q. Le ${ }^{1}$, Carlos A. Serrano ${ }^{1}$, \\ Laura D. Mydlarz ${ }^{3}$, Betty J. Scarbrough ${ }^{3}$, Kevin A. Schug ${ }^{1,2}$, Bryan W. Brooks ${ }^{4}$, \\ James P. Grover ${ }^{2,3, *}$
}

\author{
${ }^{1}$ Department of Chemistry and Biochemistry, and ${ }^{2}$ Program in Environmental and Earth Sciences, \\ University of Texas at Arlington, Box 19065, Arlington, Texas 76019, USA \\ ${ }^{3}$ Department of Biology, University of Texas at Arlington, Box 19498, Arlington, Texas 76019, USA \\ ${ }^{4}$ Department of Environmental Science and Center for Reservoir and Aquatic Systems Research, Baylor University,
} One Bear Place \#97266, Waco, Texas 76798, USA

\begin{abstract}
The haptophyte flagellate Prymnesium parvum forms blooms in brackish waters and produces toxins that harm aquatic organisms. Batch cultures of $P$. parvum were grown in phosphorus-limited artificial seawater medium with 3 treatments: no aeration or buffering, continuous aeration, and buffering to a high, basic $\mathrm{pH}$. Over a period of $32 \mathrm{~d}$, frequent samples were taken to determine: cell abundance; cellular composition of carbon $(\mathrm{C})$, nitrogen $(\mathrm{N})$, and phosphorus $(\mathrm{P})$; culture $\mathrm{pH}_{\text {; }}$ and hemolytic activity. Only $\mathrm{pH}$ differed significantly among media treatments: it was basic in all treatments after $10 \mathrm{~d}$ of culture, but consistently highest in the buffered medium treatment. In all treatments, exponential population growth was observed during the first $10 \mathrm{~d}$ of culture, at rates of about 0.4 to $0.6 \mathrm{~d}^{-1}$. The cell quota for $\mathrm{P}$ declined rapidly over the first $8 \mathrm{~d}$ of culture and more slowly thereafter. A transition from exponential growth to stationary phase occurred over 10 to $21 \mathrm{~d}$ of culture. Population growth rate was related to cell quota for P according to Droop's equation, with an estimated quota for zero growth of about $5 \mathrm{fmol} \mathrm{cell}^{-1}$. In all cultures, high hemolytic activity was seen on Days 8 and 12. All but one culture displayed oscillations of hemolytic activity thereafter. At times of high hemolytic activity, the cell quota for P was $<100 \mathrm{fmol} \mathrm{cell}^{-1}$ and the cellular C:P ratio was at or above the Redfield ratio of 106 .
\end{abstract}

KEY WORDS: Harmful algae · Phytoplankton · Blooms · Toxins · Cell quota $\cdot$ Nutrient limitation · Phosphorus Resale or republication not permitted without written consent of the publisher

\section{INTRODUCTION}

The haptophyte alga Prymnesium parvum is a unicellular flagellate that grows primarily in brackish waters and produces toxins that disrupt aquatic ecosystems (Edvardsen \& Imai 2006, Sunda et al. 2006). While primarily phototrophic, it is capable of phagotrophy (Nygaard \& Tobiesen 1993, Tillmann 1998) and tolerates a broad range of salinities and temperatures (Larsen et al. 1993, Baker et al. 2007, 2009). For $>50 \mathrm{yr}$, blooms of this alga have been responsible for massive fish kills worldwide (Reich \& Aschner 1947 , Sunda et al. 2006). Toxins produced by P. parvum affect a variety of other aquatic organisms, including other species of algae, protists, and zooplankton (e.g. Koski et al. 1999, Fistarol et al. 2003, 2005, Tillmann 2003, Sopanen et al. 2006). Therefore, blooms of this species have potentially far-reaching effects on aquatic food webs, generating considerable interest from the scientific, environmental management, and public sectors.

A variety of assays have been employed to quantify these biological responses to Prymnesium parvum (Brooks et al. 2010). Among the assays reviewed and compared by Brooks et al. (2010), acute mortality to a larval fish model and in vitro lysis of red blood cells 
represented 2 of the most sensitive assays for assessing the toxicity associated with P. parvum. Choice of a toxicity assay depends on the objectives of a study, and because the hemolytic assay provides relatively rapid information for a toxicological response, it was used here to examine variation in hemolytic toxicity over time in laboratory cultures of $P$. parvum (modification of Eschbach et al. 2001).

Factors associated with the toxicity of Prymnesium parvum were recently reviewed by Granéli \& Salomon (2010). They proposed that the abundance and stage of population growth were important, with older and denser populations being more toxic than young, sparse populations. As a population grows in a nutrientlimited medium, cellular nutrient content falls, growth slows, and toxicity rises (Dafni et al. 1972, Johansson \& Granéli 1999, Granéli \& Johansson 2003). Concurrently, pH can increase as $\mathrm{CO}_{2}$ is removed from growth media (Grover et al. 2007). Some studies have found that high $\mathrm{pH}$ increases the toxic activity of $P$. parvum (Shilo \& Aschner 1953, Valenti et al. 2010), while others have found the opposite (Padilla 1970, Igarashi et al. 1998). Aeration can also increase the toxicity of $P$. parvum (Igarashi et al. 1995), prompting suggestions that strong wind-mixing might enhance the toxicity of blooms (Granéli \& Salomon 2010).

In the present study, Prymnesium parvum was grown in P-limited batch cultures for $32 \mathrm{~d}$ with frequent sampling, to document the dynamics of cell abundance, cellular $\mathrm{C}, \mathrm{N}$ and $\mathrm{P}$ composition, $\mathrm{pH}$, and hemolytic toxicity. We hypothesized that toxic activity would rise appreciably as populations became phosphorus-limited, and we intended to resolve the timing of this event. To explore the influence of $\mathrm{pH}$ and $\mathrm{CO}_{2}$ availability, cultures were grown in a standard growth medium, a medium buffered at a basic $\mathrm{pH}$, and an aerated medium. We hypothesized that toxic activity would be altered by buffering and aeration.

\section{MATERIALS AND METHODS}

Experimental design. This experiment observed in vitro growth of Prymnesium parvum under P-limited conditions over $32 \mathrm{~d}$. Three different growth media were used. The standard treatment was a modified $f / 2$ artificial seawater (ASW) medium (described in the following subsection). The buffered treatment used the same medium, maintaining $\mathrm{pH}$ at between 8.8 and 9.6 by using $1 \mathrm{~g} \mathrm{l}^{-1} \mathrm{~N}$-[Tris(hydroxymethyl)methyl]-3aminopropane-sulfonic acid (TAPS, Sigma-Aldrich). The aerated treatment used the standard culture medium, but was continuously aerated using filtered $(0.2 \mu \mathrm{m})$, humidified, ambient air via aquarium pump at a pressure of $260 \pm 90 \mathrm{kPa}$, providing about 2 to $5 \mathrm{ml}$ $\mathrm{s}^{-1}$ of airflow. All cultures were sampled periodically for determinations of cell abundance, cellular $\mathrm{C}, \mathrm{N}$ and $\mathrm{P}$ composition, culture $\mathrm{pH}$, and hemolytic toxicity.

In vitro cultures. A modification of the ASW culture medium developed by Baker et al. (2007) was used. Artificial seawater (Kester et al. 1967) was reduced to a salinity of $6.0 \pm 0.3 \mathrm{psu}$ by dilution with ultrapure $18 \mathrm{M} \Omega \mathrm{cm}^{-1}$ water (Millipore), followed by enrichment with $\mathrm{f} / 2$ concentrations of nitrogen and trace metals (McLachlan 1973), using equimolar ferric chloride substituted for ferrous ammonium sulfate to preclude toxic effects of ammonium (Grover et al. 2007). The concentration of $\mathrm{P}$ was reduced to $1.8 \mu \mathrm{M}, 5 \%$ of the standard value for $f / 2$ enrichment, producing a molar $\mathrm{N}: \mathrm{P}$ ratio of 489, which was found to enhance the toxicity of Prymnesium parvum in preliminary cultures. Each culture was grown in a $5 \mathrm{l}$ glass carboy with a hose nipple $1 \mathrm{~cm}$ from the base, which was used to bubble a constant stream of air into those cultures receiving the aeration treatment. The mouth of each carboy was loosely covered with an inverted $250 \mathrm{ml}$ plastic beaker allowing air exchange while minimizing contamination.

A non-axenic strain of Prymnesium parvum isolated in Texas (UTEX LL 2797, Culture Collection of Algae, University of Texas, Austin, TX) was grown to stationarity in stock cultures using ASW medium and the full f/2 enrichment of nutrients including P. Experimental cultures were inoculated with $5 \mathrm{ml}$ of stock culture and incubated at $20^{\circ} \mathrm{C}$, with a $12 \mathrm{~h}$ dark: $12 \mathrm{~h}$ light photoperiod and an irradiance of 150 to $200 \mu \mathrm{mol}$ photons $\mathrm{m}^{-2} \mathrm{~s}^{-1}$ using fluorescent lighting. For each treatment, a blank was prepared that consisted of media preparation, but no culture inoculation, to control for any effects of medium chemistry arising in the absence of P. parvum.

Sampling and analysis. Cultures were sampled at the same time of day on Day 0, daily from Day 4 to 11 , every other day from Day 12 to 20, and then every $4 \mathrm{~d}$ until Day 32. Samples for determinations of cell abundance were preserved with modified Lugol's solution (Throndsen 1978) and counted microscopically using gridded Sedgwick-Rafter slides. To determine cellular $\mathrm{P}$ composition, samples of $50 \mathrm{ml}$ were passed through Whatman GF/F filters and the collected particulates were digested with persulfate (Menzel \& Corwin 1965) and analyzed for soluble reactive $\mathrm{P}$ (Strickland \& Parsons 1972). To determine cellular $\mathrm{C}$ and $\mathrm{N}$ compositions, samples of $50 \mathrm{ml}$ were passed through precombusted Whatman GF/F filters and the collected particulates were combusted in a $\mathrm{CHN}$ analyzer (Perkin-Elmer Series 2200). As indicators of cellular nutrient status, cell quota for $\mathrm{P}$ was calculated as the particulate $\mathrm{P}$ concentration divided by cell density, and cellular $\mathrm{C}: \mathrm{P}$ and $\mathrm{N}: \mathrm{P}$ molar ratios were calculated from the particulate $C, N$, and $P$ compositions. 
Hemolytic toxicity was measured on culture supernatants by a modified erythrocyte lysis assay (ELA; Eschbach et al. 2001, Brooks et al. 2010, Schug et al. 2010) conducted on the same day as sampling. An aliquot of $500 \mu \mathrm{l}$ of whole culture was centrifuged at $2500 \times g$ for 5 min to obtain supernatant for ELA. Percent lysis of sheep erythrocytes (Innovative Research) was determined in a suspension in a plasma-like homogenized buffer medium (HBM) carrier composed of $90 \%$ RPMI-1640 (Sigma-Aldrich) with 10\% water and sodium heparin anti-coagulant (SigmaAldrich) at $0.005 \mathrm{mg} \mathrm{ml}^{-1}$ final concentration. This red blood cell suspension (RBCS) was standardized by hemacytometer count to $1.00 \pm 0.05 \times 10^{7}$ cells ml$^{-1}$. Serial dilutions in HBM were calibrated for optical density at $600 \mathrm{~nm}$, and all further RBCS were prepared to a desired optical density. Supernatant samples and blanks of $20 \mu \mathrm{l}$ were added to $330 \mu \mathrm{l}$ aliquots of RBCS in a microtiter plate. The change in absorption at $414 \mathrm{~nm}$ was used to measure hemoglobin released from lysed erythrocytes as a result of the toxic activity of Prymnesium parvum, using a spectrophotometric plate reader (Synergy 2, BioTek Instruments). A calibration curve for percent lysis was constructed by combining unlysed RBCS and RBCS lysed to known percentages by sonication, in known proportions (7-point calibration curve with triplicates). Percent lysis of samples and blanks was calculated from this calibration curve. The percent lysis of culture samples was then corrected by subtracting that of method blanks. Typical blank corrections ranged from 0.0 to $4.0 \%$.

Statistical analysis. One-way analysis of variance (ANOVA) followed by contrasts using Tukey's honestly significant difference (Blair \& Taylor 2008) were used to compare means of the 3 treatments (standard, buffered, and aerated) for samples collected on the same day. The population growth rate of Prymnesium parvum was modeled as a function of cell quota using a time series approach. The population growth rate $(\mu)$ over each sampling interval was calculated for each culture as:

$$
\mu=\frac{\ln N_{1}-\ln N_{0}}{t_{1}-t_{0}}
$$

where $N_{1}$ and $N_{0}$ are abundances of $P$. parvum at successive times $t_{1}$ and $t_{0}$, respectively. The average cell quota over each sampling interval was calculated from quotas at times $t_{1}$ and $t_{0}$. Using nonlinear regression, the resulting population growth rates $(\mu)$ were then fitted to average quota $(Q)$ using Droop's (1973) equation:

$$
\mu=\mu_{\max }^{\prime}\left(1-\frac{Q_{\min }}{Q}\right)
$$

where $\mu_{\max }^{\prime}$ is the maximal growth rate and $Q_{\min }$ is the quota at which growth goes to zero. All statistical analyses were conducted using Statistica 6.0 (Statsoft).

\section{RESULTS}

Populations of Prymnesium parvum displayed exponential growth from Day 4 to 10 in all cultures (Fig. 1A). Populations did not become stationary until about $21 \mathrm{~d}$ of culture, and in all cultures there was a long period of decelerating growth from Day 10 to 21 . The exponential growth rate in each culture was calculated by regressing the natural logarithm of abundance versus time for Days 4 to 10 (Table 1). These growth rates did not differ significantly between treatments $(p>0.05)$. The stationary abundance in each culture was estimated by averaging the abundances observed on Days 24 to 32 (Table 1). These stationary abundances did not differ significantly between treatments $(p>0.05)$.

At the initiation of cultures, quotas of P per cell were high, because inocula were transferred from stock cultures containing $36 \mu \mathrm{M}$, the standard concentration for $f / 2$ growth medium, while experimental cultures had a lower P concentration of $1.8 \mu \mathrm{M}$. Cell quotas of $\mathrm{P}$ declined rapidly in all treatments for the first $8 \mathrm{~d}$ of culture, decreased more slowly until Day 20, and remained low thereafter (Fig. 1B). Population growth slowed as the cell quota decreased from exponential to stationary phase. The cell quota during stationary phase was estimated by averaging the quotas observed on Days 24 to 32 (Table 1). These stationary quotas did not differ significantly between treatments $(\mathrm{p}>0.05)$.

Cellular C:P and N:P ratios were highly correlated $(r=0.96$ for all samples). At the initiation of cultures, C:P was about 100; it was somewhat lower for Days 4 to 7, was again about 100 on Day 8, and then rose steadily until the end of the experiment (Fig. 1C). Cellular C:P during stationary phase was estimated by averaging the quotas observed on Days 24 to 32 (Table 1). These stationary $\mathrm{C}: \mathrm{P}$ ratios did not differ significantly between treatments $(p>0.05)$.

For the standard treatment, $\mathrm{pH}$ was just below 7 until Day 8, when it began increasing to a peak of 8.6 on Day 14 (Fig. 1D); pH then remained at about 8.5 until Day 20 and decreased slowly until it reached 7.2 on Day 32. For the aerated treatment, $\mathrm{pH}$ followed a similar pattern to the standard treatment until Day 11, but was higher by about 0.5 units; $\mathrm{pH}$ in the aerated treatment peaked at 8.7 on Day 11, dropped to 8.0 on Day 12, and then remained within 0.5 units of 8.0 for the remainder of the experiment. For the buffered treatment, $\mathrm{pH}$ was within 0.5 units of 9.0 for the entire exper- 

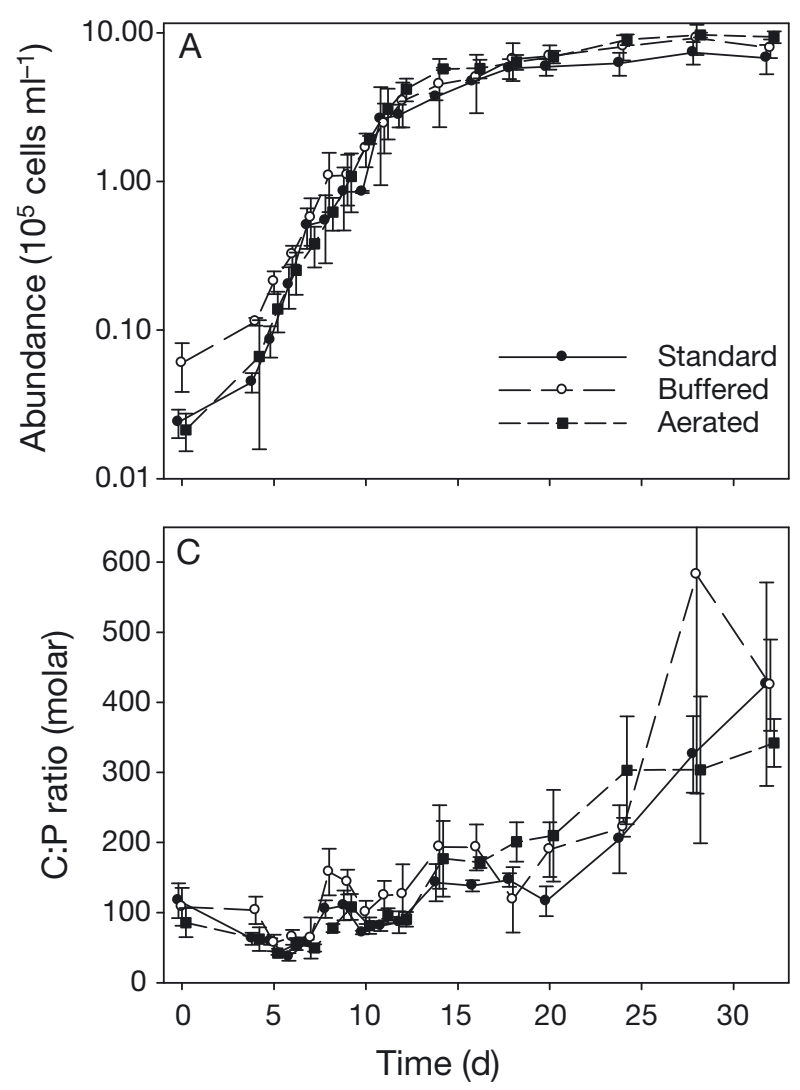
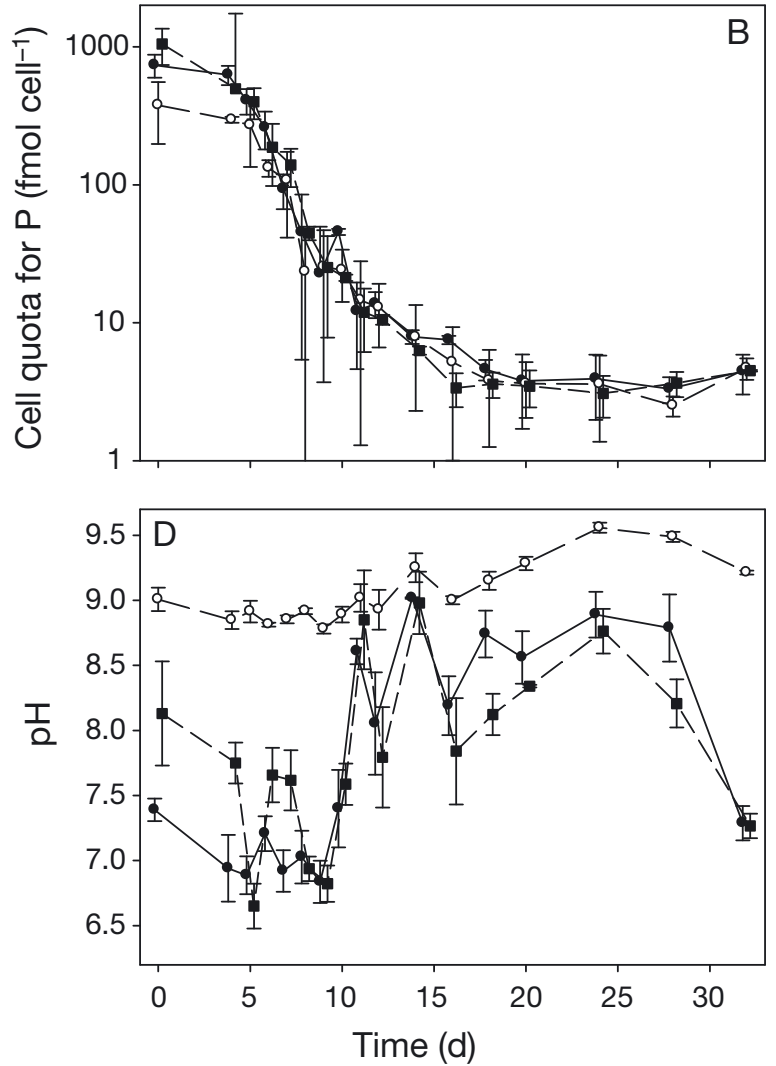

Fig. 1. Dynamics of batch cultures of Prymnesium parvum. (A) Abundance, (B) cell quota for P, (C) cellular C:P ratio, and (D) culture $\mathrm{pH}$. Filled circles and solid lines: standard treatment; open circles and dashed lines: buffered treatment; solid squares and dashed lines: aerated treatment (mean $\pm \mathrm{SD}, \mathrm{n}=3$ )

Table 1. Selected quantities in cultures of Prymnesium parvum (mean $\pm \mathrm{SE}, \mathrm{n}=3$ )

\begin{tabular}{|lccc|}
\hline Quantity & \multicolumn{2}{c|}{$\begin{array}{c}\text { Treatment } \\
\text { Buffered }\end{array}$} & Aerated \\
\cline { 3 - 4 } & Standard & $0.44 \pm 0.039$ & $0.58 \pm 0.069$ \\
\hline Exponential growth rate $\left(\mathrm{d}^{-1}\right.$ ), Days 4-10 & $0.51 \pm 0.049$ & $8.4 \pm 0.92$ & $9.3 \pm 0.08$ \\
Stationary abundance $\left(10^{5}{\text { cells } \mathrm{ml}^{-1} \text { ), Days } 24-32}_{\text {Cell quota for P (fmol cell }}^{-1}\right.$ ), Days $24-32$ & $6.8 \pm 0.64$ & $4.9 \pm 0.52$ & $4.8 \pm 0.32$ \\
Cellular C:P (molar), Days 24-32 & $5.4 \pm 0.75$ & $409 \pm 49$ & $316 \pm 11$ \\
\hline
\end{tabular}

iment. At all but 2 sampling times (Days 11 and 14), pH was significantly higher in the buffered treatment than in the standard or aerated treatments $(p<0.05)$.

The 2 parameters of Droop's equation $\left(\mu_{\max }^{\prime}\right.$ and $Q_{\text {min }}$ ) were estimated after pooling data from all experimental treatments (Fig. 2, Table 2), because preliminary analyses of separate treatments produced statistically similar parameter estimates. Data from the first sampling interval (Days 0 to 4 ) were not included in the analysis because there was an initial lag in growth, and 1 datum from the second interval (Days 4 to 5 ) in 1 culture was also deleted as an outlier.

In all cultures, hemolytic activity as percent lysis was negligible $(<5 \%)$ for the first $6 \mathrm{~d}$ of culture. It then increased rapidly in the late exponential phase of growth. To make comparisons between different population growth phases and abundances, raw percent hemolytic activity was divided by cell concentration (Fig. 3). An initial peak of hemolytic activity per cell occurred on Day 8 in all treatments, followed by a decline until Day 11 and then another peak on Day 12. Thereafter, in all but one of the standard treatment cultures, hemolytic activity displayed synchronized cycles of increasing period. When expressed as hemolytic activity per cell (Fig. 3), the amplitude of these cycles diminished as abundance increased, while peaks of raw hemolytic activity ( $\%$ lysis) exceeded $80 \%$ on Days 18 and 28. Synchronized minima of hemolytic 


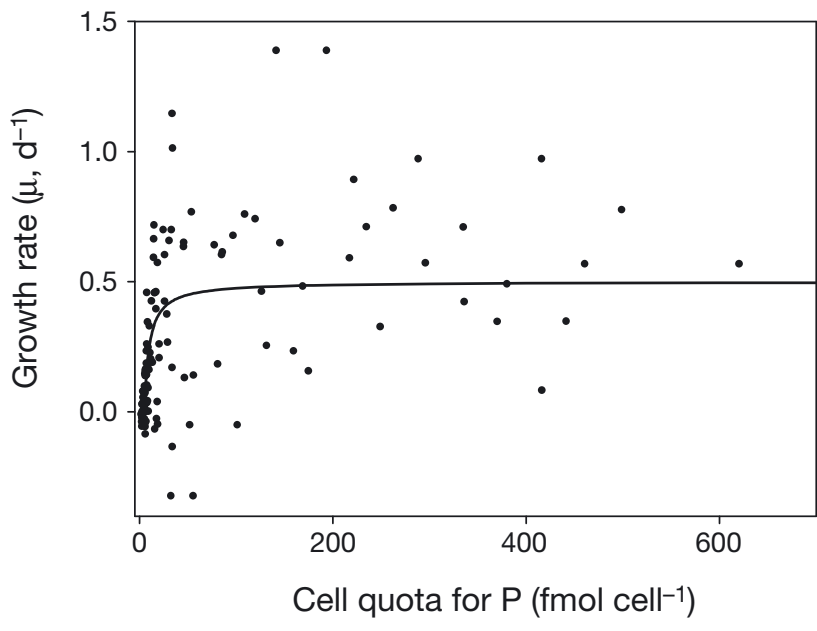

Fig. 2. Nonlinear regression fitting Droop's equation to growth rates of Prymnesium parvum estimated from abundance and cell quota. Line shows fitted curve with parameters from Table 2

Table 2. Results of nonlinear regression using Droop's equation to model population growth in cultures of Prymnesium parvum. $\mu_{\text {max }}^{\prime}$ : maximal growth rate; $Q_{\min }$ : quota at which growth goes to zero

\begin{tabular}{|lcc|}
\hline Quantity & Estimate & Standard error \\
\hline$\mu_{\text {max }}^{\prime}\left(\mathrm{d}^{-1}\right)$ & 0.50 & 0.034 \\
$Q_{\min }\left(\mathrm{fmol} \mathrm{cell}^{-1}\right)$ & 5.0 & 0.39 \\
Overall $F$ for regression & 112.0 & \\
Overall $\mathrm{p}$ for regression & $<0.001$ & \\
$\mathrm{R}^{2}$ for regression & 0.64 & \\
$\mathrm{n}$ & 134 & \\
\hline
\end{tabular}

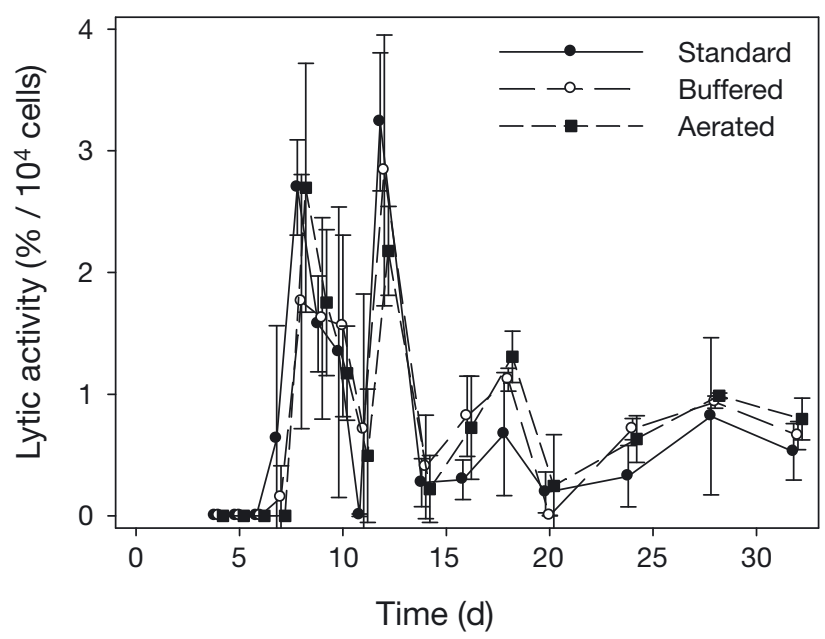

Fig. 3. Hemolytic activity in triplicate (standard, buffered, and aerated) cultures of Prymnesium parvum over a $32 \mathrm{~d}$ culture period (mean $\pm \mathrm{SD}, \mathrm{n}=3$ ) activity occurred on Days 14 and 20, in all but one of the standard treatment cultures. Hemolytic activity did not differ significantly between treatments on any day ( $p>0.05)$, whether expressed on a per cell basis or as raw percent lysis.

Despite these dynamic variations, hemolytic activity was associated with cellular P status during population growth. Because experimental treatments displayed similar dynamics, average values of all 9 cultures were used to examine these associations (Fig. 4). Early in culture growth, hemolytic activity was low $(<1 \%$ lysis $10^{-4}$ cells), accompanied by indicators of high cellular $P$ status: cell quota for $\mathrm{P}>100 \mathrm{fmol} \mathrm{cell}{ }^{-1}$, cellular C:P ratio $<50$, and cellular N:P ratio $<10$. On Day 8 , the first peak of hemolytic activity, reaching about $3 \%$ lysis $10^{-4}$ cells, occurred as the cell quota for $\mathrm{P}$ dropped below $100 \mathrm{fmol} \mathrm{cell}^{-1}$ and the cellular C:P ratio increased to about the Redfield (1958) ratio of 106, while the cellular N:P ratio remained $<10$ (Fig. 4). At this time, the cell quota for $\mathrm{P}$ was still far above the estimated minimal quota for growth $\left(5 \mathrm{fmol} \mathrm{cell}^{-1}\right.$; Table 2), and the growth rate was not yet limited by a low P quota (Fig. 2). During the subsequent transition to stationary phase, hemolytic activity oscillated between 0.3 and $1 \%$ lysis $10^{-4}$ cells, while the cell quota for P decreased below $20 \mathrm{fmol} \mathrm{cell}^{-1}$ and the cellular C:P and N:P ratios rose steadily above the Redfield values of 106 and 16 (Fig. 4). At this stage, the growth rate was $\mathrm{P}$ limited (Fig. 2).

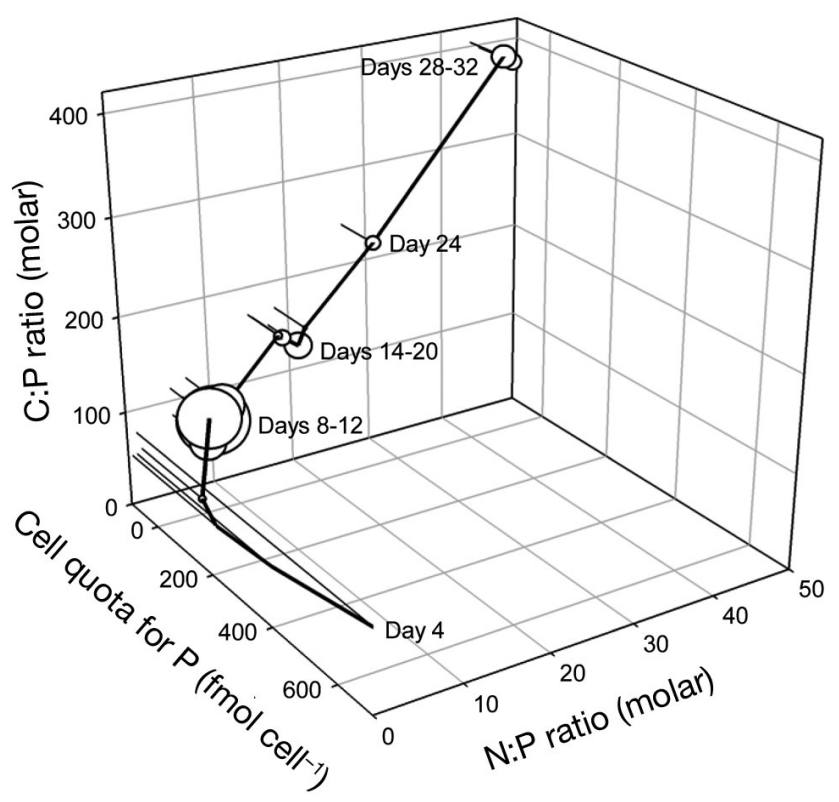

Fig. 4. Trajectory of cellular phosphorus status and hemolytic activity in cultures of Prymnesium parvum; data markers show average values for all 9 cultures, with marker size proportional to hemolytic activity ( $\%$ lysis per $10^{4}$ cells) 


\section{DISCUSSION}

Toxicity of Prymnesium parvum has long been associated with nutrient limitation, particularly by P (Dafni et al. 1972, Granéli \& Johansson 2003). High hemolytic activity has been observed in steady state, semicontinuous P-limited cultures accompanied by $\mathrm{P}$ quotas of about 6 to $10 \mathrm{fmol} \mathrm{cell}^{-1}$ (Johansson \& Granéli 1999, Uronen et al. 2005). During our study, a transition from P sufficiency to P limitation was observed, permitting analysis of the coupled dynamics of decreasing cellular $\mathrm{P}$ status and increasing toxic activity. We have estimated that population growth ceases when the P quota drops to about $5 \mathrm{fmol} \mathrm{cell}^{-1}$. Given the evident scatter in the data (Fig. 2), this estimate must be treated cautiously. Nevertheless, it is clear from Fig. 1 that as the $P$ quota drops below $10 \mathrm{fmol} \mathrm{cell}^{-1}$, population growth slows. The time that this threshold was reached varied between Days 11 and 18 during the growth of these cultures. Although population growth ceased at about $5 \mathrm{fmol} \mathrm{cell}^{-1}$, continued hemolytic activity in later samples suggested that $P$. parvum remained metabolically active and produced toxins as the $\mathrm{P}$ quota dropped further to between 1 and $2 \mathrm{fmol} \mathrm{cell}^{-1}$ by the end of the experiment.

In all cultures, an initial peak of hemolytic activity occurred around Days 8 to 10 . During this time P quota ranges were from 20 to $100 \mathrm{fmol} \mathrm{cell}^{-1}$ among cultures, several times higher than the level at which growth ceases. Though raw hemolytic activity of cultures was modest at this time (20 to $30 \%$ ), this activity was produced by a relatively small number of cells, compared to later times during culturing. On Day 12, all cultures exhibited very high raw hemolytic activity $(>90 \%$ ), when quotas had dropped below $20 \mathrm{fmol} \mathrm{cell}^{-1}$ and growth was clearly decelerating. These observations suggest that toxin production and release by Prymnesium parvum is induced when the $\mathrm{P}$ quota drops below a threshold of about $100 \mathrm{fmol} \mathrm{cell}^{-1}$.

Interestingly, using the cellular C:P ratio as an indicator of nutritional status, hemolytic toxicity is strongly associated with ratios exceeding the classical Redfield (1958) ratio of 106 (Johansson \& Granéli 1999, Uronen et al. 2005, Fig. 4 of the present study). In P-limited semicontinuous cultures of Prymnesium parvum with high hemolytic activity, the P quota was about 6 to $10 \mathrm{fmol} \mathrm{cell}^{-1}$, and, in N-limited cultures with comparable toxicity, it was about 16 to $40 \mathrm{fmol} \mathrm{cell}^{-1}$ (Johansson \& Granéli 1999, Uronen et al. 2005). Together, these observations suggest that toxicity associated with some field populations of $P$. parvum could be predicted from cellular phosphorus status. Because blooms of P. parvum are often nearly monospecific (Sunda et al. 2006, Roelke et al. 2010), it should be possible to sample field populations and determine cellular $\mathrm{P}$ status, to see whether quotas below $100 \mathrm{fmol} \mathrm{cell}^{-1}$ and cellular C:P ratios above 100 are associated with ambient toxicity to aquatic organisms. Such measurements would likely be most useful in clearly P-limited habitats. Limitation by $\mathrm{N}$ enhances toxicity of $P$. parvum compared to nutrient sufficiency, though apparently not as strongly as P-limitation (Johansson \& Granéli 1999, Uronen et al. 2005). The cellular N:P ratio is associated with toxic activity (Uronen et al. 2005, Fig. 4 of the present study), and might also be a useful indicator. However, at shallow sites, detrital seston could interfere with measurements of cellular nutrient status.

The coupling between cell quota and growth rate is an important aspect of a microorganism's ability to compete for a nutrient. When cells can accumulate stored nutrient far in excess of $Q_{\min }$ extended periods of growth are possible in environments where nutrient concentration varies (Grover 1991a). When inoculated into these low $\mathrm{P}$ experimental cultures from P-rich stock cultures, P quotas of Prymnesium parvum averaged $720 \mathrm{fmol} \mathrm{cell}^{-1}$, roughly 100 times the minimal quota at which growth vanishes, echoing previous findings that $P$. parvum has great flexibility in cellular P composition (Uronen et al. 2005). This storage capacity lies towards the high end of the range for other algae, which store 7 to 270 times the minimal quota for P (Morel 1987, Sandgren 1988, Grover 1991b). Thus, this observation adds to other indications that P. parvum is adapted to P limitation, such as genes for highaffinity P transporters (La Claire 2006), the ability to grow at very low P concentration (Baker et al. 2009), and mixotrophy (Nygaard \& Tobiesen 1993).

After the initial peaks of high hemolytic activity on Days 8 and 12, all but one culture exhibited synchronized oscillations of hemolytic activity with subsequent peaks on Days 18 and 28, suggesting cycles with a period of from 4 to $10 \mathrm{~d}$. Similar cycles of hemolytic activity with periods of from 3 to $5 \mathrm{~d}$ are suggested in the data of Uronen et al. (2005) for both P- and $\mathrm{N}$-limited semicontinuous cultures. Daily cycles in hemolytic toxicity occur in the closely related haptophyte species Chrysochromulina polylepis (Eschbach et al. 2005). Peaks in the magnitude of toxicity occurred late in the dark phase of the photoperiod, coinciding with the S-phase of the cell cycle (Eschbach et al. 2005). In contrast, cycles with periods of several days were observed for Prymnesium parvum cultures in the present study and by Uronen et al. (2005). There are many differences among these studies, and the results do not necessarily conflict. Eschbach et al. (2005) sampled with high frequency over $72 \mathrm{~h}$ during Days 4 to 7 from cultures that were grown for $12 \mathrm{~d}$, Uronen et al. (2005) sampled daily from Days 16 to 26 when populations were approximately at steady state, while we sampled with lower frequency over $32 \mathrm{~d}$ of 
culture. It is possible that daily cycles of toxicity occurred, but were missed in studies with daily or less frequent sampling, and that longer period cycles would have been observed by Eschbach et al. (2005) had their observations continued.

Except for $\mathrm{pH}$, none of the properties measured here differed significantly among standard, buffered, and aerated cultures. Although $\mathrm{pH}$ was from 0.5 to 2 units higher in buffered cultures than in other treatments, toxicity did not differ. There are contradictory prior results on the relationship of the toxic activity of Prymnesium parvum to $\mathrm{pH}$, especially when toxicity to fish and hemolytic activity are compared. High $\mathrm{pH}$ is associated with high toxicity to fish and cladocerans in some studies (e.g. Shilo \& Aschner 1953, Valenti et al. 2010), but with low hemolytic activity in others (e.g. Padilla 1970, Igarashi et al. 1998). The finding that hemolytic activity was unaffected by culture $\mathrm{pH}$ in the present study does not necessarily contradict the idea that $\mathrm{pH}$ affects the toxic activity of $P$. parvum. Many prior studies have involved comparisons across at least $3 \mathrm{pH}$ units, a larger difference than compared here. Our results apparently contradict earlier findings that aeration promotes toxic activity (Granéli \& Salomon 2010), but the airflow imposed here was low compared to the very vigorous aeration of $100 \mathrm{ml} \mathrm{s}^{-1}$ associated with elevated toxic activity (Igarashi et al. 1995). In that same study, aeration at $10 \mathrm{ml} \mathrm{s}^{-1}$ enhanced abundance, but not toxic activity.

Blooms of Prymnesium parvum have been responsible for fish kills worldwide (Reich \& Aschner 1947, Sunda et al. 2006), and toxic blooms have increased in prevalence in the inland waters of Texas and other parts of the southwestern United States since the 1980s (Southard et al. 2010). In Texas reservoirs, blooms of $P$. parvum typically occur in winter, a time period when concentrations of nutrients, including $\mathrm{P}$, can increase in these water bodies (Sterner 1994). A puzzling observation is that blooms with abundant populations are sometimes not toxic to fish (Roelke et al. 2007, 2010). By analogy to the culture dynamics observed here, we offer some potential explanations. Toxin production and related ambient toxicity produced by blooms may not become high unless nutrients are depleted (Johansson \& Granéli 1999). Such depletion can occur during bloom development, as it does during batch culture in the laboratory. Presumably, nutrient depletion takes several days to develop, and events of flushing and nutrient loading could prevent nutrient depletion and the associated toxicity even while fueling further population growth. A bloom might never become nutrient-limited, but, even when it does, if toxic activity cycles with a period of 6 to $10 \mathrm{~d}$, it might not be observed in samples taken to assess toxicity. Finally, ambient toxicity to aquatic organisms may vary with the many factors that commonly vary in inland waters, including salinity and temperature (Baker et al. 2007), pH (Valenti et al. 2010), and possibly bacterial abundance and activity (Granéli \& Salomon 2010).

Acknowledgements. This work was supported by Grant No.182582 from the Texas Parks \& Wildlife Department. We thank D. L. Roelke and 2 anonymous referees for comments on the manuscript.

\section{LITERATURE CITED}

Baker JW, Grover JP, Brooks BW, Ureña-Boeck F, and others (2007) Growth and toxicity of Prymnesium parvum (Haptophyta) as a function of salinity, light and temperature. J Phycol 43:219-227

Baker JW, Grover JP, Ramachandrannair R, Black C and others (2009) Growth at the edge of the niche: an experimental study of the harmful alga Prymnesium parvum. Limnol Oceanogr 54:1679-1687

Blair RC, Taylor RA (2008) Biostatistics for the health sciences. Prentice-Hall, Upper Saddle River, NJ

Brooks BW, James SV, Valenti TW, Urena-Boeck F and others (2010) Comparative toxicity of Prymnesium parvum in inland waters. J Am Water Resour Assoc 46:45-62

Dafni Z, Ulitzer S, Shilo M (1972) Influence of light and phosphate on toxin production and growth of Prymnesium parvum. J Gen Microbiol 70:199-207

Droop MR (1973) Nutrient limitation in algae. J Phycol 9: 264-272

Edvardsen B, Imai I (2006) The ecology of harmful flagellates within Prymnesiophyceae and Raphidophyceae. In: Granéli E, Turner J (eds) The ecology of harmful algae. Springer, Berlin, p 67-80

Eschbach E, Scharsack JP, John U, Medlin LK (2001) Improved erythrocyte lysis assay in microtitre plates for sensitive detection and efficient measurement of hemolytic compounds from ichthyotoxic algae. J Appl Toxicol 21:513-519

- Eschbach E, John U, Beckerman M, Cembella AD and others (2005) Cell cycle dependent expression of toxicity by the ichthyotoxic prymnesiophyte Chrysochromulina polylepis. Aquat Microb Ecol 39:85-95

Fistarol GO, Legrand C, Granéli E (2003) Allelopathic effect of Prymnesium parvum on a natural phytoplankton community. Mar Ecol Prog Ser 255:115-125

> Fistarol GO, Legrand C, Granéli E (2005) Allelopathic effect on a nutrient-limited phytoplankton species. Aquat Microb Ecol 41:153-161

Granéli E, Johansson N (2003) Increase in the production of allelopathic substances by Prymnesium parvum cells grown under $\mathrm{N}$ - or P-deficient conditions. Harmful Algae 2:135-145

Granéli E, Salomon PS (2010) Factors influencing allelopathy and toxicity in Prymnesium parvum. J Am Water Resour Assoc 46:108-120

Grover JP (1991a) Resource competition in a variable environment: phytoplankton growing according to the variable-internal-stores model. Am Nat 138:811-835

Grover JP (1991b) Dynamics of competition among microalgae in variable environments: experimental tests of alternative models. Oikos 62:231-243

> Grover JP, Baker JW, Ureña-Boeck F, Brooks BW and others (2007) Laboratory tests of ammonium and barley straw 
extract as agents to suppress abundance of the harmful alga Prymnesium parvum and its toxicity to fish. Water Res 41:2503-2512

Igarashi T, Oshima Y, Murata M, and others (1995) Chemical studies on prymnesins isolated from Prymnesium parvum. In: Lassus P, Arzul G, Erard-Le Denn E, Gentien P, Marcaillou-Le Baut C (eds) Harmful marine algal blooms. Proc 6 th international conference on toxic marine phytoplankton. Lavoisier Publishing, Paris, p 303-308

Igarashi T, Aritake S, Yasumoto T (1998) Biological activities of prymnesin-2 isolated from a red tide alga Prymnesium parvum. Nat Toxins 6:35-41

Johansson N, Granéli E (1999) Influence of different nutrient conditions on cell density, chemical composition and toxicity of Prymnesium parvum (Haptophyta) in semi-continuous cultures. J Exp Mar Biol Ecol 239:243-258

Kester DR, Duedall IW, Connors DN, Pytkowicz RM (1967) Preparation of artificial sea water. Limnol Oceanogr 12: 176-179

Koski M, Rosenberg M, Viitasalo M, Tanskanen A, and others (1999) Is Prymnesium patelliferum toxic for copepods? Grazing, egg production, and egestion of the calanoid copepod Eurytemora affinis in mixtures of 'good' and 'bad' food. ICES J Mar Sci 56:131-139

La Claire JW (2006) Analysis of expressed sequence tags from the harmful alga, Prymnesium parvum (Prymnesiophyceae, Haptophyta). Mar Biotechnol 8:534-546

Larsen A, Eikrem W, Paasche E (1993) Growth and toxicity in Prymnesium patelliferum (Prymnesiophyceae) isolated from Norwegian waters. Can J Bot 71:1357-1362

McLachlan J (1973) Growth media - marine. In: Stein J (ed) Handbook of phycological methods: culture methods and growth measurements. Cambridge University Press, Cambridge, p 25-51

Menzel DW, Corwin N (1965) The measurement of total phosphorus in seawater based on the liberation of organically bound fractions by persulfate oxidation. Limnol Oceanogr 10:280-282

Morel FMM (1987) Kinetics of nutrient uptake and growth in phytoplankton. J Phycol 23:137-150

> Nygaard K, Tobiesen A (1993) Bacterivory in algae: a survival strategy during nutrient limitation. Limnol Oceanogr 38: 273-279

Padilla GM (1970) Growth and toxigenesis of the chrysomonad Prymnesium parvum as a function of salinity. J Protozool 17:456-462

Redfield AC (1958) The biological control of chemical factors in the environment. Am Sci 46:205-221

Reich K, Aschner M (1947) Mass development and control of the phytoflagellate Prymnesium parvum in fish ponds in Palestine. Palestine J Bot Jerusalem Ser 4:14-23

Roelke DL, Errera R, Kiesling R, Brooks BW and others (2007) Effects of nutrient enrichment on Prymnesium parvum

Editorial responsibility: Patricia Glibert,

Cambridge, Maryland, USA population dynamics and toxicity: results from field experiments, Lake Possum Kingdom, USA. Aquat Microb Ecol 46:125-140

Roelke DL, Gable GM, Valenti TW, Grover JP and others (2010) Hydraulic flushing as a Prymnesium parvum bloom-terminating mechanism in a subtropical lake. Harmful Algae 9:323-332

Sandgren CD (1988) The ecology of chrysophyte flagellates: their growth and perennation strategies as freshwater phytoplankton. In: Sandgren CD (ed) Growth and reproductive strategies of freshwater phytoplankton. Cambridge University Press, Cambridge, p 9-104

Schug KA, Skingel TR, Spencer SE, Serrano CA, and others (2010) Hemolysis, fish mortality, and LC-ESI-MS of cultured crude and fractionated golden alga (Prymnesium parvum). J Am Water Resour Assoc 46:33-44

Shilo M, Aschner M (1953) Factors governing the toxicity of cultures containing the phytoflagellate Prymnesium parvum Carter. J Gen Microbiol 8:333-343

Sopanen S, Koski M, Kuuppo P, Uronen P, Legrand C, Tamminen T (2006) Toxic haptophyte Prymnesium parvum affects grazing, survival, egestion, and egg production of the calanoid copepods Eurytemora affinis and Acartia bifilosa. Mar Ecol Prog Ser 327:223-232

Southard GM, Fries LT, Barkoh A (2010) Prymnesium parvum: the Texas experience. J Am Water Resour Assoc 46:14-23

Sterner RW (1994) Seasonal and spatial patterns in macro and micro nutrient limitation in Joe Pool Lake, Texas. Limnol Oceanogr 39:535-550

Strickland JDH, Parsons TR (1972) A practical handbook of seawater analysis, 2nd edn. Bull Fish Res Board Can 167:1-310

Sunda WG, Granéli E, Gobler CJ (2006) Positive feedback and the development and persistence of ecosystem disruptive algal blooms. J Phycol 42:963-974

Throndsen J (1978) Preservation and storage. In: Sournia A (ed) Phytoplankton manual. Monographs on oceanographic methodology. UNESCO, Paris, p 70-71

Tillmann U (1998) Phagotrophy by a plastidic haptophyte, Prymnesium parvum. Aquat Microb Ecol 14:155-160

Tillmann U (2003) Kill and eat your predator: a winning strategy of the planktonic flagellate Prymnesium parvum. Aquat Microb Ecol 32:73-84

Uronen P, Lehtinen S, Legrand C, Kuuppo P, Tamminen T (2005) Haemolytic activity and allelopathy of the haptophyte Prymnesium parvum in nutrient-limited and balanced growth conditions. Mar Ecol Prog Ser 299: 137-148

Valenti Jr TW, James SV, Lahousse MJ, Schug KA and others (2010) A mechanistic explanation for pH-dependent ambient aquatic toxicity of Prymnesium parvum Carter. Toxicon 55:990-998

Submitted: February 22, 2010; Accepted: August 8, 2010

Proofs received from author(s): September 17, 2010 